\title{
Erzincan ili hayvansal atık kaynaklı biyogaz potansiyelinin değerlendirilmesine yönelik biyogaz tesisi senaryoları
}

\author{
Biyogas plant scenarios for evaluating biogas potential from animal waste of Erzincan \\ province
}

\author{
Aslıhan KURNUC SEYHAN*1,a , Anıl BADEM ${ }^{2, b}$ \\ ${ }^{I}$ Erzincan Binali Yıldırım Üniversitesi, Mühendislik Fakültesi, Makine Mühendisliği Bölümü, 24100, Erzincan \\ ${ }^{2}$ Oltan Köleoğlu Enerji, 61290, Trabzon
}

• Geliş tarihi / Received: 28.05.2020 • Düzeltilerek geliş tarihi / Received in revised form: 23.10.2020 • Kabul tarihi / Accepted: 03.01.2021

\begin{abstract}
Öz
Hayvan atıklarından biyogaz üretimi gibi atıkların enerji teknolojisine uygulanması, Türkiye de dâhil olmak üzere gelişmekte olan birçok ülkede sürdürülebilir enerji geliştirme hedeflerine ulaşmak için en iyi araçlardan biri olarak kabul edilmektedir. Türkiye, çok sayıda hayvan çiftliği ile önemli bir potansiyele sahip olsa da bugüne kadar biyogaz üretimi için potansiyel gerçekleşmemiştir. Bu makale, Türkiye'de alternatif bir enerji üretimi kaynağı olarak hayvan atıklarından biyogaz üretimi yoluyla atıkların enerji teknolojisine potansiyel uygulanmasının vurgulanmasını amaçlamaktadır. Hayvan atıkları gibi yenilenebilir hammaddelerin anaerobik sindirimi, biyogaz şeklinde temiz enerji üretimi için ileriye dönük bir teknoloji olarak bilinmektedir. Bu çalışmada Erzincan ilinin hayvansal atık kaynaklı enerji potansiyeli hesaplanmıştır. Bulgular, Erzincan'daki hayvan atıklarından yaklaşık 15.5 milyon $\mathrm{m}^{3} / \mathrm{y} 1$ biyogaz potansiyelinin üretilebileceğini göstermektedir. $\mathrm{Bu}$ doğrultuda, Erzincan ve ilçelerinin mesafeleri, atık kapasiteleri ve ekonomik verimliliği göz önüne alındığında, 0.5 MW, 1.2 MW ve $2.4 \mathrm{MW}$ kurulu güce sahip 3 farklı biyogaz santrali senaryosu hazırlanmıştır. Bu tesislerin yatırım maliyetleri ve her bir tesis için gerekli olan yatırımın geri ödeme süreleri hesaplanmıştır. Araştırmaya dayanarak, Erzincan'da biyogaz üretimi ile hayvan atıklarının enerjiye dönüştürülmesi açısından birçok firsat araştırılabilir. Bölgede, küçük boyutlarda olmak üzere, önerilen sayıdan daha fazla sayıda biyogaz tesisi kurmak da mümkündür.
\end{abstract}

Anahtar kelimeler: Biyogaz üretimi, Hayvan atıkları, Yenilenebilir enerji

\begin{abstract}
In many developing countries, including Turkey, the implementation of waste to energy technology is known as one of the most effective approaches to reach sustainable energy development targets. Although, Turkey with a large number of farm animals has a significant potential, but this potential unrealized for biogas production so far. This study aims to highlight the potential implementation of waste to energy technology via the production of biogas from animal waste as an alternative energy generation in Turkey. Anaerobic digestion of renewable feed stocks such as animal waste has been known as a promising technology for the production of clean energy in the form of biogas. In this study, the energy potential of Erzincan province animal waste was calculated. Findings show that approximately 15.5 million $\mathrm{m}^{3}$ year-1 biogas potential can be produced from animal waste in Erzincan. Accordingly, considering the distances, waste capacities and economic efficiency of Erzincan and its districts, 3 different biogas power plant scenarios with $0.5 \mathrm{MW}, 1.2 \mathrm{MW}$ and 2.4 MW installed power have been prepared. Appropriate facility capacities, investment costs of these facilities and payback times of the investment required for each facility were calculated. Based on the investigation, numerous opportunities could be explored in terms of turning animal waste to energy by biogas production in Erzincan. It is also possible to establish more biogas plants in the region, in smaller sizes, than the number recommended.
\end{abstract}

Keywords: Biogas production, Animal waste, Renewable energy

\footnotetext{
*a Aslıhan KURNUÇ SEYHAN; akurnuc@erzincan.edu.tr, Tel: (0532) 7716572, orcid.org/ 0000-0002-7614-7303

${ }^{\mathrm{b}}$ orcid.org/0000-0002-9492-9819
} 


\section{Giriş}

Sanayileşme ve nüfus artışı beraberinde artan enerji talebini ortaya çıkarmıştır. Fosil yakıtlar dünyanın enerji arzında en büyük paya sahiptir ve özellikle çevre kirliliği ve küresel isınma olmak üzere mevcut çevre sorunlarına neden olmaktadır. Enerji üretiminde fosil yakıtların yaygın olarak kullanılması ve bu yakıt rezervlerinin ömrünün sınırlı olması ile tüm dünyada yeni ve yenilenebilir enerji kaynaklarına olan eğilim artmaktadır (Abdeshahian vd., 2016).

Küresel ölçekte enerji gereksinimi, üretim giderlerinin minimize edilmesi ve çevre bilinci oluşturularak karşılanmaktadır. Yenilenebilir enerji kaynaklarının sürdürülebilir, çevre dostu ve ekonomik olması enerji üretimi için son derece önemlidir. Yenilenebilir enerji kaynaklarından biri olan biyokütle, fosil yakıtlara bağımlılığı azaltarak alternatif bir enerji kaynağı olarak karşımıza çıkmaktadır (Gürdil vd., 2015).

2017 y1lı itibariyle yenilenebilir enerji, dünya toplam nihai enerji tüketiminin yaklaşık \%20.3' ünü oluşturmuştur. Geleneksel ve modern biyokütle enerjisi, 2017 yllında dünya toplam enerji tüketiminde \%12.4'lük bir paya sahiptir. Bu payın \% 7.4 ile en büyük oranı geleneksel biyokütle olarak adlandırılan ve gelişmekte olan ülkelerde ısınma ve pişirme amaciyla kullanılan biyokütle oluşturmaktadır. \%5 ile modern biyokütle ise, $\% 2.2$ ile endüstride biyokütleden 1s1 kullanımı, $\% 1.4$ ile binalarda 1sı kullanımı, \%1 ile ulaşım, $\% 0.4$ ile biyokütleden elektrik enerjisi eldesinden oluşmaktadır (REN21, 2019).

Biyokütle, hayvan gübresi, ormancılık ve tarımsal kalıntılar, belediye ve tarımsal-endüstriyel katı atıklar gibi çok çeşitli organik atıkları içeren sürdürülebilir bir yenilenebilir enerji kaynağıdır. Biyokütle sürdürülebilir kalkınmaya katk1 sağlamasının yanında, dünya nüfusunun tamamında enerji güvenliği de sağlar. Ayrıca biyokütleden enerji elde edilmesi proseslerinde ortaya çıan $\mathrm{CO}_{2}$, fotosentez yoluyla organik maddelerin büyümesi ve gelişmesi sırasında atmosferden alınan $\mathrm{CO}_{2}$ ' ye eşdeğer olduğundan biyokütle enerjisi karbon nötrdür böylece sera gazı emisyonlarını da azaltmış olur. Bunun yanı sıra, kullanılabilirlik ve iyi bilinen dönüşüm teknolojileri nedeniyle biyokütle, talebi karşılamak ve enerji arz güvenliğini sağlamak amacıyla çok yakın bir zamanda önemli enerji kaynaklarından biri olacaktır (Ekpeni vd., 2014; Ar, 2018). Çünkü son değerlendirmeler enerji tasarruflu ve çevre dostu bir teknoloji olan anaerobik sindirim yoluyla üretilen biyogazın diğer biyoenerji formlarına göre önemli avantajlar sağladığını belirtmektedir (Achinas vd., 2017).

Biyokütle kaynakları kullanılarak temelde biyoetanol, biyodizel ve biyogaz olarak üç farklı biyoyakıt formu elde edilir. Biyoetanol üretiminde, selüloz içeriği yüksek odun ve orman ürünleri atıkları veya buğday, arpa, misır, patates gibi nişasta içeren ürünler, şeker içeren şeker pancarı, meyve gibi biyokütle kaynakları kullanılmaktadır. (Öztürk, 2012). Biyodizel üretiminde atık yemeklik yağlar, bitkisel yağlar (kanola, kolza, soya fasulyesi, ayçiçeği, hurma yağı vb.), hayvansal yağlar (büyükbaş, küçükbaş, kanatlı yağı vb.) kullanılmaktadır (Demirbaş, 2011). Biyogaz üretiminde ise hayvansal atıklar, bitkisel atıklar ve organik içerikli kentsel atıklar kullanılmaktadır (Akbulut ve Dikici, 2014). Hayvansal atıkları, uygun şekilde yönetilmedikleri takdirde çevre için tehlikeli olacak ana organik atıklardan biridir. Hayvan gübresi, yüksek konsantrasyonda azot $(\mathrm{N})$ ve fosfor $(\mathrm{P})$ gibi besin elementlerini içerir ki, bu da besin dengesizliğine ve çevre kirliliğine neden olur. Ayrıca, hayvan gübresi antibiyotikle ve büyüme hormonu ağır metaller gibi bazı zararlı maddelerin kalıntılarını içermektedir. Böylece hayvan gübresindeki mikroorganizmalar çevreyi kirletebilir ve bu da insan hastalıklarının ortaya çıkmasına neden olabilir. Bu bağlamda, hayvan gübresinin bertaraf edilmesinin, hava, toprak ve su kaynaklarını kirleten, çevre üzerinde kirletici etkiye neden olduğu bulunmuştur. Bu nedenle, hayvan gübresi ve bulamaçların anaerobik sindirim prosesiyle işlenmesi, biyogaz olarak sürdürülebilir enerji kaynağı üretimi ile kaliteli gübre üretme, kokuların ve mikrobiyal patojenlerin azaltılması gibi faydalı sonuçlara sahiptir (Hol-Nielsen vd., 2009; Gebrezgabher vd., 2010).

Abdeshahian vd. (2016) Malezya'daki çiftlik hayvanı atıklarından biyogaz üretim potansiyeli üzerine yapmış oldukları bir çalışmada hayvan atıklarının kullanılmasının sadece sürdürülebilir yeni ve yenilenebilir enerji üretimi için değil, aynı zamanda uygun atık yönetiminin uygulanması için de yararlı olduğunu belirterek yönetilmeyen hayvan atıklarının çevre üzerindeki potansiyel olumsuz kirletici etkisinin azaltılmasına yardımc1 olabileceğini ifade etmişlerdir. Hayvan atıklarından yıllık 4589.49 milyon-m $\mathrm{m}^{3} / \mathrm{y} 1 \mathrm{l}$ biyogaz üretilebileceğini hesaplayarak, bu atıkların biyogaz enerjisi ve elektrik enerjisi üretimi için verimli bir şekilde kullanılabilecek umut verici düşük maliyetli ve sürdürülebilir enerji kaynağı olduğu kanaatine varmışlardır. $\mathrm{Bu}$ gibi teknolojik 
uygulamanın değerlendirilmesinde, Tayland, Malezya ve Myanmar gibi bölgedeki birçok gelişmekte olan ülkede yaygın olarak incelendiğini ve bu ülkelerdeki biyogaz üretiminin çoğunun sadece küçük ölçekli operasyonlar olarak yapıldığını ve üretilen biyogazın şu anda pişirme ve aydınlatma için kullanıldığını belirtmişlerdir. Scarlat vd. (2018) de Avrupa bölgesindeki hayvan çiftlikleri için benzer bir çalışma yapmıştır. Bir başka çalışmada, Meksika'daki organik atıklardan biyogaz üretiminin potansiyelini ve enerji üretimi için kullanımını araştırılmış, biyogaz üretim tesisinin inşası için teorik, teknik ve ekonomik potansiyel kapasiteye sahip 391 farklı yer seçimi yapılmıştır (Rios ve Kaltschmitt, 2016). Bazı başka çalışmalar da organik atıklardan üretilebilecek biyogaz miktarını tahmin edilmiş ve biyogazın enerji üretimi ve ulaştırma sektörleri için enerji gereksinimlerinin sağlanmasına ne kadar katkıda bulunabileceği önerilmiştir $(\mathrm{Cu} \quad$ vd., 2015; Lonnqvist vd., 2015; Uddin vd., 2016; Moreda, 2016).

Biyogaz teknolojisinin, yerel ve kırsal alanlarda enerji ihtiyaçlarının karşılanması, patojenlerin azaltılması, atık kaynaklı koku problemine çözüm sunmas1, kimyasal gübrelerin yerine, toprak kalite, verim ve yapısını geliştiren işlenmiş organik gübre olarak kullanılabilmesi ve modern teknolojilerle üretilebildiği gibi, organik atıkların bulunduğu bölgelerde ilkel yöntemlerle de üretilerek kullanıma hazır hale getirilebilmesi biyogazı daha değerli hale getirmektedir (Çevik, 2016; Özer, 2017). Biyogaz, hemen hemen her türlü organik maddenin anaerobik sindiriminden kaynaklanan yenilenebilir bir enerji kaynağını temsil eder. Hayvan gübresi anaerobik sindirimde büyük bir metan üretim potansiyeline sahip olduğundan biyogaz üretiminde en yaygın kullanılan organik maddelerden biridir (Agayev ve Ugurlu, 2011). Türkiye, önemli biyogaz potansiyeline sahip ülkelerden biridir. Bununla birlikte, hayvan atıklarının biyogaz üretimi için hammadde olarak kullanımı sadece birkaç yerde uygulanmakta ve kapasite şu anda yetersiz kullanılmaktadır. Türkiye'de hayvanc1lık yönetimi henüz istenen seviyelere ulaşamamıştır.

Türkiye'de küçük ölçekli çiftlik hayvanlarının yaygınlığı, sağlam bir yönetim sistemi kurmak ve biyogaz üretimi için geri kazanılan hayvan gübresi miktarını artırmak için önemli engellerden biridir. Türkiye 81 ilden oluşmaktadır ve her ilin farklı sosyal ve ekonomik yapıları vardır. Tarım, ülke ve Türkiye'deki birçok il için hala önemli bir sosyoekonomik faktördür (Ersoy ve Ugurlu, 2020). Türkiye, 2009 y1lından sonra, büyük ölçüde artan hayvancılık teşviklerinden dolayı hayvan sayısında artış eğilimi yaşamıştır. Türkiye İstatistik Kurumu (TÜiK) verilerine göre, 2015 yılında büyükbaş hayvan sayısı (sığır ve manda) 14.13 milyon iken, küçükbaş hayvan sayısı (koyun ve keçi) büyük geviş getiren hayvanların eğilimine benzer bir artış eğilimi ile 41.92 milyona ulaşmıştır (TÜİK, 2019).

Türkiye, çok sayıda hayvan çiftliği ile önemli bir potansiyele sahip olsa da, bugüne kadar biyogaz üretimi için potansiyel gerçekleşmemiştir. Enerji üretimi Türkiye'nin en önemli kalkınma önceliklerinden biri olmakla birlikte, yerli enerji üretimi enerji talebinin\%40'ını aşmamıştır (Demirbas, 2003). Türkiye'de hidroelektrik santralleri, doğal gaz, kömür, linyit, fuel oil ve jeotermal enerji ile ateşlenen termik santraller elektrik üretiminin başlıca kaynaklarıdır (Capik et al., 2012). Türkiye'deki tüm yenilenebilir enerji kaynaklarından biyokütle enerjisi potansiyeli, güneş enerjisi potansiyelinden sonra yani ikinci sirada yer almaktadır (Acaroglu and Aydogan, 2012). Son yillarda, hem küçük hem de büyük ölçekli biyogaz tesisleri için biyogaz teknolojilerinin olgunlaşması ve ekonomik sürdürülebilirlik açısından büyük adımlar atılmaktadır. Türkiye'nin toplam kurulu gücü 2015 y1lı sonunda 73.14 GW (Kilickaplan vd., 2017) ve biyokütle enerjisinin kurulu gücü 344.7 MW'tır, bu da toplam kurulu enerjinin \%0.47'sine karşıllık gelmektedir. 2016 yılı itibariyle, çoğunlukla belediye depolama alanları ve atık su aritma tesislerinde bulunan ve sadece 15 'inde hayvan gübresi hammadde olarak kullanılan yaklaşık 70 biyogaz enerji tesisi bulunmakta (EA, 2016) iken şu an 82 biyogaz, biyokütle, atık1 1s1 ve pirolitik yağ enerji santrallerinin toplam kurulu gücü 467.37 MW'dır. Lisanslı biyokütle santrallerinde yine çöpten biyogaz üreten santraller ilk sırada yer almaktadır (EA,2020).

Türkiye'de hayvancılık, yüksek ekonomik değere sahip olup, biyogaz üretimi için yüksek hayvan gübresi potansiyelini göstermektedir. Türkiye'nin toplam hayvan biyogaz potansiyeli $\% 68$ sığır, $\% 5$ küçükbaş hayvan ve $\% 27$ kümes hayvanlarından gelmektedir (Avcioglu ve Turker, 2012). Türkiye'nin hayvansal atıklardan bölge, yöre ve işletme bazında elde edilebilecek biyogaz miktarı ve enerji potansiyelini belirleyen birçok çalışma yapılmıştır (Eryılmaz vd., 2015; Ilgar, 2016; Özer, 2017; Akyürek, 2019; Yağlı ve Koç, 2019). Özer (2017) Ardahan ili için yaptığı çalışmada hayvansal atık ve tahıldan elde edilebilecek enerji potansiyeli belirlemiştir. 2015 yılına ait hayvan popülasyonu ve tarımsal ürünlerin ilçelere göre dağılım verilerini TÜİK'ten almıştır. Her bir gübre 
türü, fiziksel ve kimyasal özelliklere bağlı olarak farklı enerji potansiyeline sahip olduğundan farklı gübre türlerinin metan potansiyellerini laboratuvar analizine dayanarak belirlemiştir. Yürük ve Erdoğmuş (2015) Türkiye İstatistik Kurumunun 2013 y1lı verilerini dikkate alarak Düzce ili ve ilçelerinde hayvansal atıklarından biyogaz potansiyelini hesaplamışlardır. Düzce ilinde bulunan 473 tesisin konum bilgilerini elde ederek bu konumlarının hepsine en yakın tesisi bulmak için kümeleme yöntemini kullanmışlardır. $\mathrm{Bu}$ tesisleri Matlab'da K-means kümeleme algoritmas1 ile konumlarına göre 5, 6, 7 ve 8 küme sayısına göre kümelemiş ve daha sonra bu kümeler tek bir küme olacak şekilde kümelenerek bir biyogaz tesisinin yaklaşı en iyi konumunu belirlemişleridir. Ancak bu konum kapasiteler gözetilmeden elde edilen konumdur.

Yapılan çalışmalar 1şığında ülke politikaları ve ekonomik sürdürülebilirlik açısından bölgesel biyogaz üretim potansiyelinin araştırılarak, bu potansiyele bağlı olarak elde edilebilecek güç miktarının hesaplanmasının önemli olduğu görülmektedir. Literatürde dünya genelinde herhangi bir ülkenin genel ve şehirler bazında biyogaz üretim potansiyelinin araştırıldığ birçok çalışmaya rastlanmakta iken ülkemiz için kısıtlı sayıda çalışma yapıldığı anlaşılmaktadır. Türkiye'nin genel biyogaz üretim potansiyeli araştırmalarının yanı sıra hayvan sayısı bakımından büyük potansiyele sahip olan şehirlerin de potansiyelinin ayrı ayrı belirlenmesi oldukça önemlidir (Yağlı ve Koç, 2019). Ülkemizde çeşitli illerinin biyogaz potansiyelinin belirlenmesine yönelik birçok çalışma mevcuttur. $\mathrm{Bu}$ çalı̧̧malarda genellikle Türkiye İstatistik Kurumu'nun (TUIK) verileri kullanılmıştır (Koçer ve Kurt, 2013; Yürük ve Erdoğmuş, 2015; Özer, 2017; Yağlı ve Koç, 2019).

Erzincan ilinde hayvanc1lı, şehir ekonomisine büyük katkı sağlamaktadır. İldeki hayvansal atık üretim miktarı yüksektir ve etkili yönetim stratejileri gerektirmektedir. Yenilenebilir enerji yatırımc1ları biyogaz üretimine özel ilgi göstermektedir ancak Erzincan'da faaliyet gösteren hayvansal atık kaynaklı biyogaz tesisi bulunmamaktadır. Literatürde de Erzincan'ın biyogaz potansiyelini net veriler üzerinden ortaya çıkartan bir çalışmaya rastlayamamış olmamız bizi $\mathrm{bu}$ çalışmayı yapmaya yönlendirmiştir. Bu çalışmada, Erzincan ili genelindeki değerlendirilmeyen hayvansal atıkların enerji potansiyelleri belirlenmiş, hayvansal atıkların taşıma mesafeleri göz önünde bulundurularak, uygun tesis kapasiteleri ile bu tesislerin yatırım maliyetleri hesaplanmıştır. Uygun tesis konumu istatistiksel yöntemlerle değil direk hayvan kapasiteleri gözetilerek belirlenmiştir.

\section{Materyal ve metot}

\subsection{Biyogaz üretim potansiyelinin belirlenmesi}

Erzincan ilinin hayvansal atık kaynaklı biyogaz potansiyelini hesaplayabilmek için alandaki mevcut organik malzeme miktarını tahmin etmek gerekir. Bu sebeple ilk adım olarak hayvan sayıları belirlenmiştir. Hayvan sayıları belirlenirken TÜIKK verileri değil, ilçe bazında büyükbaş hayvan sayıları için Erzincan Damızlık Sığır Yetiştiricileri Birliği verileri, küçükbaş ve kanatlı hayvan sayıları için ise Gıda, Tarım ve Hayvancılık İl Müdürlüğü verileri kullanılarak oluşturulmuştur. Buna göre Erzincan merkez ve ilçelerinde bulunan çiftliklerdeki hayvan sayıları Tablo 1'de görülmektedir (Kurnuç Seyhan ve Badem, 2018).

Tablo 1. Erzincan merkez ve ilçelerinde bulunan çiftliklerdeki hayvan sayıları

\begin{tabular}{|c|c|c|c|c|c|c|c|c|}
\hline \multirow[t]{2}{*}{ İLÇELER } & \multirow[t]{2}{*}{$\begin{array}{r}\text { BÜYÜKBAŞ-2017 } \\
\text { Soy+Ön Soy Kütük } \\
\end{array}$} & \multicolumn{4}{|c|}{ KANATLI-2015 } & \multicolumn{3}{|c|}{ KÜÇÜKBAŞ-2015 } \\
\hline & & Yumurta & Broiler & Diğer* & Toplam & Koyun & Keçi & Toplam \\
\hline MERKEZ & 24646 & 430000 & 135000 & 1390 & 566390 & 119039 & 2605 & 121644 \\
\hline İLİÇ & 533 & 1425 & & 90 & 1515 & 59022 & 9424 & 68446 \\
\hline KEMAH & 1435 & 1500 & & 302 & 1802 & 54586 & 6482 & 61068 \\
\hline OTLUKBELİ & 2363 & 3400 & & 175 & 3575 & 2523 & 258 & 2781 \\
\hline TERCAN & 15222 & 5497 & & 2465 & 7962 & 87256 & 4999 & 92255 \\
\hline REFAHİYE & 6208 & 3000 & & 560 & 3560 & 3457 & 1513 & 4970 \\
\hline KEMALIYE & 324 & 200 & & 20 & 220 & 14125 & 14349 & 28474 \\
\hline ÜZÜMLÜ & 5213 & 750 & 139500 & 190 & 140440 & 40509 & 800 & 41309 \\
\hline ÇAYIRLI & 8923 & 3000 & & 750 & 3750 & 21610 & 2161 & 23771 \\
\hline TOPLAM & 64867 & 448772 & 274500 & 5942 & 729214 & 402127 & 42591 & 444718 \\
\hline
\end{tabular}


Bölgedeki işletmelerde kayıtlı olan hayvan sayıları baz alınarak merkez ve ilçelerin yıllık hayvansal atık üretim miktarı ve bu atıklardan elde edilebilecek biyogaz ve metan potansiyelleri hesaplanmışır. Potansiyel hesaplamalarında yapılan kabul değerleri Tablo 2'de sunulmuştur.
Buna göre merkez ve ilçeler bazında atıklardan üretilebilecek biyogaz, metan ve elektrik miktarlarının dağılımı Tablo 3' te görülmektedir. Erzincan'daki hayvan atıklarından yaklaşık 15.5 milyon $\mathrm{m}^{3} / \mathrm{y} 1 \mathrm{l}$ biyogaz potansiyelinin üretilebileceği görülmektedir.

Tablo 2. Potansiyel hesaplamalarında yapılan kabuller

\begin{tabular}{llcl}
\hline PARAMETRE & DEĞER & BíRiM & Referans \\
\hline Fermente Gübre Fiyatı & 15 & USD/ton & SELEDA, 2020 \\
Doğalgaz Birim Fiyat1 & 0.25 & USD/m³ doğalgaz & BOTAŞ, 2020 \\
Elektrik Birim Fiyatı (YEKDEM) & 0.133 & USD/kWh elektrik & EPDK, 2020 \\
Euro/USD Paritesi (Nisan, 2020) & 1.07 & Euro/USD & TCMB, 2020 \\
\hline
\end{tabular}

Tablo 3. Erzincan merkez ve ilçelerindeki biyogaz üretim potansiyeli

\begin{tabular}{|c|c|c|c|c|c|c|c|c|c|}
\hline İLÇELER & $\begin{array}{l}\text { Büyükbaş } \\
\text { Atık } \\
\text { Miktarı } \\
\text { (ton/yıl) }\end{array}$ & $\begin{array}{l}\text { Kanatlı } \\
\text { Atık } \\
\text { Miktarı } \\
\text { (ton/yl) }\end{array}$ & $\begin{array}{l}\text { Küçükbaş } \\
\text { Atık } \\
\text { Miktarı } \\
\text { (ton/yıl) }\end{array}$ & $\begin{array}{l}\text { Toplam } \\
\text { Atık } \\
\text { Miktarı } \\
\text { (ton/yıl) }\end{array}$ & $\begin{array}{l}\text { Biyogaz } \\
\text { Potansiyeli } \\
\left(\mathbf{m}^{3} / \mathbf{y l}\right)\end{array}$ & $\begin{array}{l}\text { Metan } \\
\text { Potansiyeli } \\
\left(\mathbf{m}^{3} / \mathbf{y l}\right)\end{array}$ & $\begin{array}{l}\text { Elektrik } \\
\text { Üretimi } \\
(\mathbf{k W h} / \mathbf{y l l})\end{array}$ & $\begin{array}{l}\text { Kurulu } \\
\text { Güç } \\
\left(\mathbf{k W}_{\mathrm{e}}\right)\end{array}$ & $\begin{array}{l}\text { Ton } \\
\text { Eşdeğer } \\
\text { Petrol } \\
\text { (TEP/yıl) }\end{array}$ \\
\hline MERKEZ & 133812 & 29503 & 11544 & 174860 & 6956896 & 4521982 & 17055108 & 1947 & 1466.74 \\
\hline İLİÇ & 2894 & 69 & 6496 & 9459 & 399286 & 259536 & 978866 & 112 & 84.18 \\
\hline КЕМАН & 7791 & 78 & 5795 & 13665 & 504058 & 327637 & 1235717 & 141 & 106.27 \\
\hline OTLUKBELİ & 12830 & 164 & 264 & 13258 & 387807 & 252075 & 950725 & 109 & 81.76 \\
\hline TERCAN & 82646 & 321 & 8755 & 91722 & 270798 & 1801019 & 6792722 & 775 & 584.17 \\
\hline REFAHIYE & 33706 & 155 & 472 & 34332 & 983451 & 639243 & 2410970 & 275 & 207.34 \\
\hline KEMALIYE & 1759 & 10 & 2702 & 4471 & 180012 & 117008 & 441307 & 50 & 37.95 \\
\hline ÜZÜMLÜ & 28303 & 9618 & 3920 & 41841 & 1845056 & 1199287 & 4523229 & 516 & 389.00 \\
\hline ÇAYIRLI & 48446 & 160 & 2256 & 50862 & 1483647 & 964371 & 3637220 & 415 & 312.80 \\
\hline TOPLAM & 352187 & 40078 & 42204 & 434469 & 15511011 & 10082157 & 38025864 & 4341 & 3270.22 \\
\hline
\end{tabular}

$\mathrm{Bu}$ potansiyelin merkez ve ilçelere göre dağılım yüzdesi Şekil 1'de görülmektedir. Erzincan ilinde üretilebilecek biyogaz potansiyelinin $\% 45^{\prime} i$ merkezden elde edilebilecek iken, merkezi ikinci sırada $\% 18$ oranla Tercan ilçesi takip etmektedir. Kemaliye ilçesi ise \%1'lik oranla en az biyogaz üretim potansiyeline sahiptir. Elektrik üretimi doğrudan biyogaz potansiyeline bağlı olduğundan aynı oranlar elektrik üretimi için de geçerli olup Erzincan ilinden yaklaşı 38 milyon $\mathrm{kWh}_{\mathrm{e}} / \mathrm{yll}$ ' lik elektrik üretimi gerçekleştirilebilir.

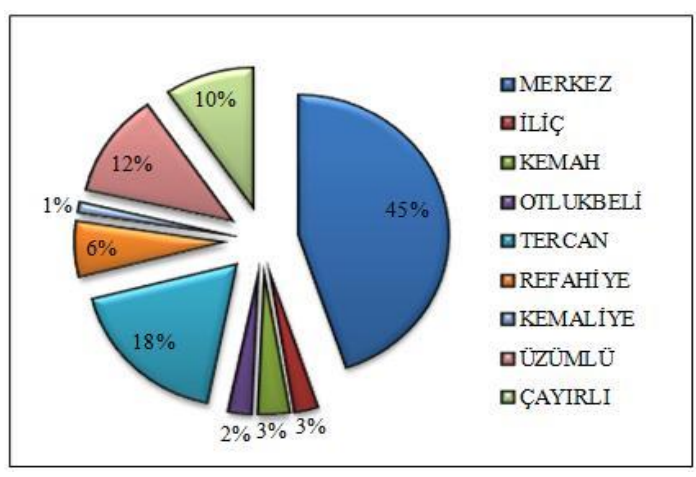

Şekil 1. Biyogaz potansiyeli dağılımı 


\subsection{Biyogaz enerji santralleri için saha seçimi}

Hayvansal atık kaynaklı biyogaz tesislerinden; atıklardan üretilen biyogazdan elektrik ve isı elde edilirken ayrıca yan ürün olarak da gübre elde edilebilmektedir. Böylece atıklar çevresel geri kazanım sağlanarak bertaraf edilmekte ve aynı atıklardan enerji geri kazanımı da sağlanmaktadır. Oluşan biyogaz gaz jeneratörlerinde yakılarak elektrik enerjisine dönüştürülerek, üretilen elektrik lokal alanda kullanılabildiği gibi elektrik şebekesine de verilebilmektedir. Biyogazın yanmasıyla oluşan 1s1 enerjisi de çeşitli uygulama alanlarında kullanılabilmektedir. Her iki çıktı da (elektrik ve 1s1) etkin bir şekilde kullanılabilirse tesis ilk yatırım maliyetini kısa sürede geri ödemektedir. Yan ürün olan fermantasyon atıkları ise, tarım işletmecisine yüksek kaliteli gübre olarak satılabilmektedir. Bu fermantasyon atıkları ham haldeki sıvı veya katı çiftlik gübresine kıyasla, bitkiler tarafindan daha rahat emilmektedir. Ayrıca ham çiftlik gübresine oranla daha az yakıcı olup genelde kokusuzdur. Hastalık oluşturucu bakteri ve parazitler de üretim sürecinde çok büyük oranda yok olmaktadır (Türker, 2008). Bu özellik kullanılacak olan organik (sıvı fermente) gübrenin ham çiftlik gübresine oranla yaklaşı $\% 10$ daha verimli olmasını sağlamaktadır (YEGM, 2020). Bu siv1 fermente gübre, biyogaz tesislerinde oldukça fazla miktarlarda oluşmaktadır. Fazla miktarda oluşmaları sebebiyle doğru bir şekilde yönetilmeleri de ayrıca önem arz etmektedir. Doğru bir atık yönetimi ile hem tarımsal araziler hem de çevre kapsamında uygun bir ürün haline dönüşebilirler (Tufaner, 2013).

Birçok yenilenebilir kaynakta olduğu gibi, çiftlik hayvanı atıklarının coğrafi konumu üzerinde herhangi bir kontrol yoktur. $\mathrm{Bu}$ nedenle, bulundukları koşullar göz önüne alındığında, ekonomik olarak faydalanılıp faydalanılmayacağını belirlemek gereklidir (Dangal vd., 2000). Hayvanı atıklarından faydalanılması kanaatine varıldığında biyogaz santralleri için en uygun sahaları bulmak amaciyla biyogaz üretimi için bölgesel farklılıklar dikkate alınarak çeşitli yaklaşım uygulanmaktadır. Potansiyel gaz depolama ve dağıtım sistemi olarak kullanılabilecek bir doğal gaz şebekesinin bulunduğu bölgelerde, saha seçim sürecinde temel öncelik, Kernel yoğunluk haritalarının (tanımlı bir arama yarıçapındaki besleme stoku miktarlarına dayalı yoğunluk değerleri haritası) yardımıyla şebekeye yakın biyokütle kaynağının yüksek kullanılabilirliği olan alanları tanımlamaktır. Doğal gaz şebekesinin yokluğunda ise, biyometanın kullanım noktaları esas olarak şehir merkezlerinde yoğunlaşmaktadır. Bu nedenle, yüksek hammadde temini olan alanlarda biyometan üretilmesinin ve biyometanın tüketici pazarına taşınmasının veya talep noktasına yakın biyometan üretilmesinin ve hammaddenin üretim sahasına taşınmasının daha uygun olup olmadığı düşünülmelidir. Mevcut hammaddenin büyük bir kısmının, digestat (biyogaz üretimi tamamlandığında, yüksek kaliteli bir gübreye dönüştürülen atık) kullanımının da gerçekleştĭgi kırsal alanlardan kaynaklanması nedeniyle, yüksek hammadde kullanılabilirliğine sahip alanlarda biyometan üretilmesinin daha uygun olduğu varsayılmıştır. Bu nedenle, doğal gaz şebekesi olmayan alanlarda yer seçimi esas olarak biyokütle besleme stokunun mevcudiyetinden kaynaklanmaktadır (Höhn vd., 2014).

Çalışma kapsamında, Erzincan iline ait ilçeler bazında elde edilebilecek enerji potansiyelleri hesaplanmıştır. İlçe bazlı hayvansal atık potansiyelinin, biyogaz enerji santrali kurulumu için ekonomik olmadığı öngörülmesi nedeniyle mesafeler göz önüne alınarak çeşitli senaryolar oluşturulmuştur. Yüksek biyokütle konsantrasyonuna sahip alanlar belirlenerek tasarlanan senaryolar ile, yakın mesafelerde bulunan ilçelerdeki hayvansal atıkların merkezi bir lokasyonda toplanarak tasarlanan tesisin verimli ve ekonomik bir şekilde çalışması hedeflenmiştir. Biyokütle kaynaklarının yüksek kullanılabilirliği dikkate alınarak ilçeler arası mesafeler 3 farklı grup içerisinde ele alınmıştır. Merkezi biyogaz tesislerinde finansal açıdan, taşıma mesafesi son derece önemlidir. $\mathrm{Bu}$ sebeple mesafe grupları belirlenerek uzaklık seviye gruplandırmaları yapılmıştır (Tablo 4). Erzincan ilçeler arası mesafeler tablosu üzerinde seviye göstergelerini de Tablo 5'te görülmektedir.

Tablo 4. Uzaklık Seviyeleri

\begin{tabular}{llc}
\hline Lejand & Uzaklık & Mesafeler(km) \\
\hline & 1.seviye & $0-25$ \\
2.seviye & $26-50$ \\
& 3.seviye & $51-70$ \\
\hline
\end{tabular}


Tablo 5. Erzincan ilçeler arası mesafeler tablosu

\begin{tabular}{|l|c|c|c|c|c|c|c|c|c|}
\hline & MERKEZ & ILİÇ & KEMAH & OTLUKBELİ & TERCAN & REFAHIYE & KEMALIYE & ÜZÜMLÜ & ÇAYIRLI \\
\hline MERKEZ & $\mathbf{0}$ & 115 & 51 & 139 & 97 & 70 & 151 & 23 & 122 \\
\hline ILIĊC & $\mathbf{1 1 5}$ & $\mathbf{0}$ & 66 & 252 & 210 & 75 & 42 & 136 & 234 \\
\hline KEMAH & 51 & 66 & $\mathbf{0}$ & 205 & 163 & 40 & 118 & 89 & 188 \\
\hline OTLUKBEL亡் & $\mathbf{1 3 9}$ & 252 & 205 & $\mathbf{0}$ & 64 & 213 & 287 & 129 & 29 \\
\hline TERCAN & $\mathbf{9 7}$ & 210 & 163 & 64 & $\mathbf{0}$ & 171 & 245 & 87 & 47 \\
\hline REFAHIYE & $\mathbf{7 0}$ & 75 & 40 & 213 & 171 & $\mathbf{0}$ & 110 & 97 & 196 \\
\hline KEMALIYE & $\mathbf{1 5 1}$ & 42 & 118 & 287 & 245 & 110 & $\mathbf{0}$ & 171 & 270 \\
\hline ÜZÜMLÜ & 23 & 136 & 89 & 129 & 87 & 97 & 171 & $\mathbf{0}$ & 105 \\
\hline ÇAYIRLI & $\mathbf{1 2 2}$ & 234 & 188 & 29 & 47 & 196 & 270 & 105 & $\mathbf{0}$ \\
\hline
\end{tabular}

Literatürde birincil enerji girişinin tipik olarak üretilen biyogazın enerji içeriğinin \%20-40'ından fazlasını karşılayamayacağı, hammaddenin, enerji dengesi negatif hale gelmeden önce gübre için yaklaşık $200 \mathrm{~km}$ ve kesimhane atığ için ise 700 km'ye kadar taşınabileceği bilgileri mevcuttur. Nakliye için mutlak bir üst sınır değerinden bahsedecek olursak, operasyonların net enerji dengesi negatif olduğunda, yani üretilenden daha fazla enerji kullanıldığı zaman bu üst sınır olmalıdır. Gübre ve saman için bu maksimum taşıma mesafesi yaklaşı $200 \mathrm{~km}$ olabilir ancak ekonomik olarak mümkün olan mesafe çok daha azdır (Berglund ve Börjesson, 2006). Ayrica bir başka çalışmada da yüksek nem içeriğine sahip hammaddelerin $20 \mathrm{~m}^{3}$ lük tankerlerde tesisin 10 $\mathrm{km}$ 'sinden daha fazla bir yarıçapından toplanamadığ 1 , düşük nem içerikli hammaddelerin ise 20 tonluk kapalı kamyonlarda $40 \mathrm{~km}$ 'lik bir yarıçap içindeki konumlardan toplanabildiği ifade edilmiştir (Dangall vd., 2000, Palm, 2010).

Erzincan ili ve ilçelerinin birbirlerine olan mesafeleri, sahip oldukları atık kapasiteleri ve ekonomiklik göz önüne alınarak maksimum $70 \mathrm{~km}$ lojistik taşıma mesafesine sahip 3 farklı biyogaz enerji santrali senaryosu ortaya çıkarılmıştır. Çalışma kapsamında, gruplandırmalar bazında tesis fizibiliteleri de yapilarak senaryolar hazırlanmıştır.

\section{Bulgular ve tartışma}

Hayvansal atıklardan biyogaz enerjisi elde etmek üzere hazırlanan projelerin ilk aşaması, bu sistemden fayda sağlayacak olan bölge halkının motivasyonu ve projeyi sahipleniciliğidir. Teknik uygulanabilirlik çalışmalarının haricinde aşağıdaki etmenlerden oluşan ekonomik değerlendirmelerin yapılmas1 gerekmektedir (Kaya ve Öztürk, 2012).

- Biyogaz sistemine hayvansal atık sağlayacak yeterli sayıda çiftlik bulunması ve atık miktarının sürdürülebilirliği,

- Fermentasyon sonucunda oluşan (susuzlaştırılmış) fermente gübre olarak kullanım olanağı,

- Anaeorobik fermentasyon sonucunda elde edilecek biyogaz (veya elektrik), gübre ve 1sının kullanım alanı,

- Sistem boyutları, alan gereksinimi, biyogaz/elektrik, 1s1 üretme kapasitesi,

- Taşıma giderleri ve lojistik

Belirtilen parametreler göz önünde bulundurularak, Erzincan ili ve ilçeleri kapsamında hayvansal atık kaynaklı 3 farklı biyogaz enerji santrali senaryosu ortaya çıkarılmış ve merkezi sistem biyogaz tesisi fizibiliteleri üzerine yoğunlaşılmıştır.

$\mathrm{Bu}$ senaryolar;

- Kemah Biyogaz Enerji Santrali

- Çayırlı Biyogaz Enerji Santrali

- Erzincan Merkez Biyogaz Enerji Santrali

şeklindedir. Biyogaz enerji santralleri için ilçe seçimi Tablo 5'den faydalanarak gerçekleştirilmiş olup Tablo 6'da sunulmuştur.

Tablo 6. Biyogaz enerji santralleri için ilçe seçimi

\begin{tabular}{cc}
\hline Enerji Santrali Projesi & İlçeler \\
\hline Kemah Biyogaz Enerji Santrali & İliç, Kemah, Refahiye \\
Çayırlı Biyogaz Enerji Santrali & Otlukbeli, Çayırlı, Tercan \\
Erzincan Merkez Biyogaz Enerji Santrali & Merkez, Üzümlü \\
\hline
\end{tabular}


Kemaliye ilçesinde hayvan sayısının azlı̆̆ hayvansal atık miktarını ve dolayısıyla bu atıklardan elde edilebilecek olan biyogaz enerjisi potansiyelini etkilemektedir. Kemaliye en az potansiyele sahip olan ilçedir. Bu sebeple Erzincan ili ve ilçelerinin birbirlerine olan mesafeleri, sahip oldukları atık kapasiteleri ve ekonomiklik göz önüne alınarak oluşturulan 3 farklı biyogaz enerji santrali senaryosu içerisinde Kemaliye ilçesi yer alamamıştır. İlçe gruplandırmalarına göre oluşturulan 3 biyogaz enerji santralinin yerleşimi harita üzerinde Şekil 2'de görülmektedir.

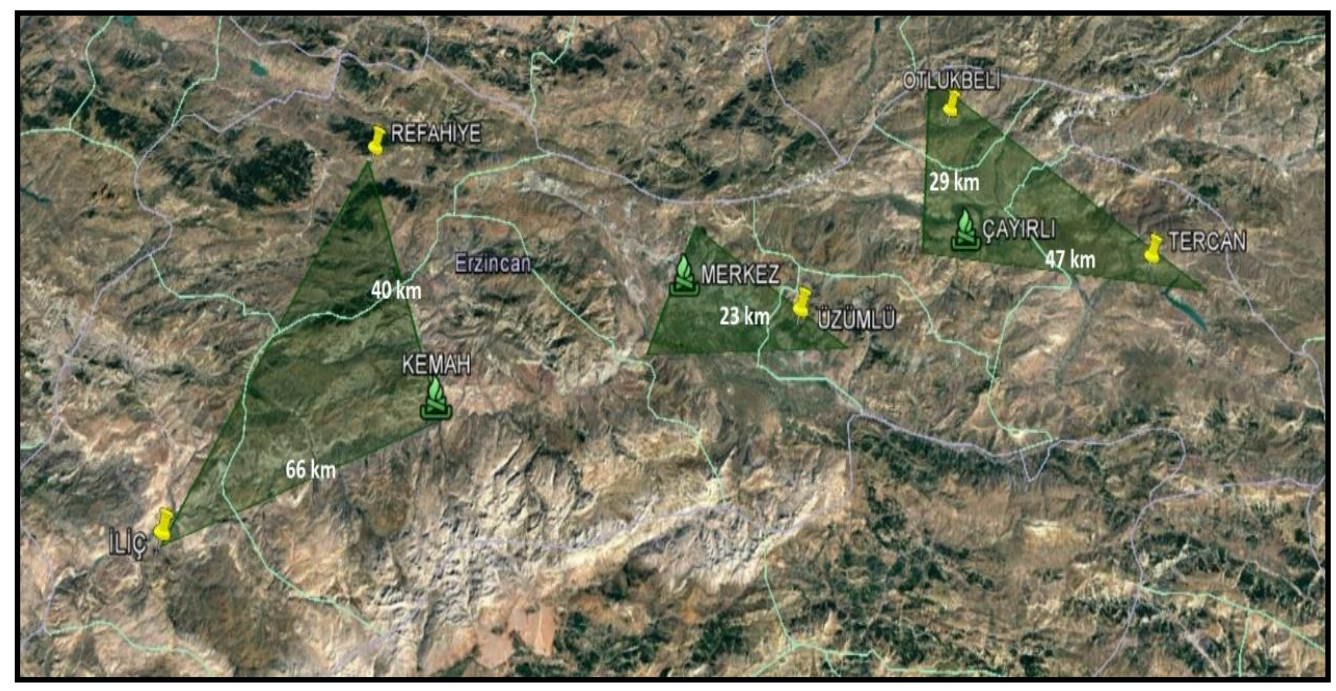

Şekil 2. Biyogaz enerji santrali yerleşimleri

Proje geliştirme giderleri, ilk yatırım maliyeti, işletme ve eğitim giderleri biyogaz enerji santrali üretim sistemi maliyetini oluşturan ana faktörlerdir. Projenin gelir getirmesi beklenen kalemleri ise; üretilen elektriğin satışından beklenen gelir, jeneratörden oluşacak sıcak suyun ekonomik olarak değerlendirilmesi ve anaerobik fermentasyon işlemi sonucu fermente olmuş substraktın gübre veya toprak iyileştirici olarak satışından elde edilebilecek gelirdir. Biyogaz tesisleri için tasarım giderleri, yerleşik kapasiteye bağlı olarak; her kW güç başına $2500-7500 €$ veya $1 \mathrm{~m}^{3}$ reaktör hacmi başına $250-700 €$ arasında değişmektedir. Biyogaz tesisleri, tasarım giderlerinin 4-7 y1l içerisinde kendisini amorti etmesi durumunda, ekonomik açıdan uygulanabilir durumdadırlar (Kaya ve Öztürk, 2012). Çalışmada hesaplamalar yapilırken, 5000 Euro/ $\mathrm{kW}_{\mathrm{e}}$ kurulu güce bağlı yatırım oranı kullanılmıştır.

Belirlenen 3 biyogaz enerji santrali projesi kapsamında bulunan ilçeler ve tasarlanan tesiste elde edilecek atık, biyogaz ve metan miktarları ile elektrik ve 1sı üretimlerini içeren fizibilite çalışması Tablo 7'de verilmiştir.

Kemah biyogaz enerji santrali, çalışma bölgesinde hayvansal atıklardan yıllık üretilebilecek biyogaz miktarı $1886795 \mathrm{~m}^{3}$ olarak hesaplanmıştır. Kemah biyogaz enerji santralinde üretilecek y1llık elektrik enerjisi miktarı $4625554 \mathrm{kWh}$ ve atık 1s1 enerjisi $\begin{array}{llllllll}\text { miktarı ise } & 4 & 356 & 987 & 122 & \text { kcal } & \text { olarak }\end{array}$ hesaplanmıştır. Santralin ilk yatırım maliyeti 2467 436 USD ve buna göre geri ödeme süresi 4.02 yıl hesaplanmıştır.

Çayırlı biyogaz enerji santrali çalışma bölgesinde hayvansal atıklardan yıllık üretilebilecek biyogaz miktarı $4642252 \mathrm{~m}^{3}$ olarak hesaplanmıştır. Çayırlı biyogaz enerji santralinde üretilecek y1llık elektrik enerjisi miktar1 $11380667 \mathrm{kWh}$ ve atık 1S1 enerjisi miktarı ise $\quad 10 \quad 719 \quad 889 \quad 091 \quad \mathrm{kcal}$ olarak hesaplanmıştır. Santralin ilk yatırım maliyeti 6070 855 USD ve buna göre geri ödeme süresi 3.96 yıl hesaplanmıştır.

Benzer şekildeki hesaplamalarla Erzincan Merkez biyogaz enerji santrali çalışma bölgesinde, hayvansal atıklardan yıllık üretilebilecek biyogaz miktarı diğer enerji santrali senaryolarına oranla 8 $801952 \mathrm{~m}^{3}$ ile en yüksek biyogaz enerjisi üretiminin gerçekleştirildiği enerji santralini temsil etmektedir. Erzincan Merkez biyogaz enerji santralinde üretilen yıllık elektrik enerjisi miktarı $21578337 \mathrm{kWh}$ ve atık 1s1 enerjisi miktarı ise 20 $325466955 \mathrm{kcal}$ olarak hesaplanmıştır. Santralin ilk yatırım maliyeti 11510656 USD ve buna göre geri ödeme süresi 4.14 yıl hesaplanmıştır.

Gübre getirileri incelendiğinde Kemah biyogaz enerji santralinin 615199 USD, Çayırlı biyogaz enerji santralinin 350643 UDS ve Erzincan Merkez biyogaz enerji santralinin ise 487577 USD gelir getirisi sağlayacağı görülmektedir. 
Tablo 7. Biyogaz enerji santralleri fizibilite çalışması

\begin{tabular}{|c|c|c|c|c|}
\hline Açıklama & $\begin{array}{l}\text { KEMAH BIYYGAZ } \\
\text { ENERJİ SANTRALI } \\
\text { (Iliç, Kemah, } \\
\text { Refahiye) }\end{array}$ & $\begin{array}{c}\text { ÇAYIRLI BIYYOGAZ } \\
\text { ENERJI SANTRALI } \\
\text { (Otlukbeli, Çayırl, } \\
\text { Tercan) }\end{array}$ & $\begin{array}{c}\text { ERZINCAN } \\
\text { MERKEZ BIYYOGAZ } \\
\text { ENERJİ SANTRALI } \\
\text { (Merkez, Üzümlü) }\end{array}$ & Birim \\
\hline \multicolumn{5}{|c|}{ Atık ve Biyogaz Üretimi Miktarı } \\
\hline Büyükbaş Atık & 44391 & 143922 & 162116 & ton/y1l \\
\hline Kanatlı Atık & 302 & 645 & 39121 & ton/y1l \\
\hline Küçükbaş Atık & 12763 & 11275 & 15464 & ton/y1l \\
\hline Biyogaz Üretimi & 1886795 & 4642252 & 8801952 & $\mathrm{~m}^{3} / \mathrm{y}_{11}$ \\
\hline Metan Üretimi & 1226417 & 3017464 & 5721269 & $\mathrm{~m}^{3} / \mathrm{y} 1 \mathrm{l}$ \\
\hline \multicolumn{5}{|c|}{ Elektrik ve Isı Üretimi } \\
\hline Elektrik Üretimi & 4625554 & 11380667 & 21578337 & $\mathrm{kWh}_{\mathrm{e}} / \mathrm{y} 1 \mathrm{l}$ \\
\hline Isı Üretimi & 4356987122 & 10719889091 & 20325466955 & $\mathrm{kcal} / \mathrm{y} 1 \mathrm{l}$ \\
\hline Kurulu Güç & 528 & 1299 & 2463 & $\mathrm{~kW}_{\mathrm{e}}$ \\
\hline \multicolumn{5}{|c|}{ Gelir ve Gider Miktarı } \\
\hline Elektrik Geliri & 615199 & 1513629 & 2869919 & $\mathrm{USD} / \mathrm{y} 1 \mathrm{l}$ \\
\hline Gübre Geliri & 129275 & 350643 & 487577 & USD/y1l \\
\hline $\begin{array}{lr}\text { Isıl } & \text { Fayda } \\
\text { (doğalgaz eşdeğeri) }\end{array}$ & 132030 & 324845 & 615923 & $\mathrm{USD} / \mathrm{y} 1 \mathrm{l}$ \\
\hline Toplam Gelir & 876503 & 2189117 & 3973419 & USD/y1l \\
\hline Toplam Gider & 262951 & 656735 & 1192026 & USD/y1l \\
\hline Net Gelir & 613552 & 1532382 & 2781393 & $\mathrm{USD} / \mathrm{y} 1 \mathrm{l}$ \\
\hline \multicolumn{5}{|c|}{ Yatırım Miktarı } \\
\hline Yatırım & 2467436 & 6070855 & 11510656 & USD \\
\hline Geri Ödeme Süresi & 4.02 & 3.96 & 4.14 & y1l \\
\hline Yatırım Oranı & 4673 & 4673 & 4673 & $\mathrm{USD} / \mathrm{kW}_{\mathrm{e}}$ \\
\hline
\end{tabular}

\section{Tartışma ve sonuçlar}

Nüfusun hızlı büyümesi nedeniyle, ülkemiz şu anda iki zorlukla karşı karşıyadır; gelecekteki kullanılabilir enerji ve atık yönetiminin güvenliğini sağlamak. Böylece yenilenebilen enerji kaynakları araştırma konusuna olan ilginin artmasıyla birlikte kullanım alanları artmakta ve kapasiteleri büyümektedir. Bu zorlukların üstesinden gelmenin en iyi yollarından birisi de temiz alternatif enerji üretimi için anaerobik sindirim gibi enerji teknolojilerine yönelik atıkların biyokütle santrallerinde işlenerek biyogaz şekline dönüştürülmesidir. Biyokütle santralleri ile elektrik, 1s1 ve biyoyakıt üretimi gibi ana ürünlerden gelir sağlanabildiği gibi bunlara ek olarak proses sirasinda elde edilen yan ürünlerin (organik gübre vb.) pazarlanması veya bu ürünlerin prosese tekrar dahil edilmesi ile de yatırımcilara ek gelir sağlanabilmektedir (Deloitte, 2020).
Sürdürülebilir çevre anlayışı ve yenilenebilir enerji kaynakları kullanımı bakımından merkezileştirilmiş biyogaz santralleri ülkemiz için büyük önem taşımaktadır. $\mathrm{Bu}$, enerjide dışa bağımlılığın azaltılmasına, yenilenebilir enerji üretimine teşvik edilmesine, daha yaşanılır mekânların oluşturulmasına katkıda bulunacaktır. $\mathrm{Bu}$ konudaki uygulamalarla yatırımların yapılmasına, araştırma ve geliştirme faaliyetlerine önem verilmelidir (Öztürk, 2017; Tolay vd., 2008). Ülkemizde yeni kanuni düzenlemelerle yenilenebilir enerji kaynaklarını kullananlara teşvik ve destekler sağlanmakta ve özendirici çalışmalar devam etmektedir. Ülkemizde bu anlamda yapılan çalışmaların sayısı arttıkça başarıyı etkileyen olumsuzluklar daha net bir şekilde ortaya çıkacak ve bu şekilde başarı kriterleri belirlenerek ileride yapilacak biyogaz tesisi projelerinin başarı seviyesi de artacaktır. 
Çalışmada Erzincan ilinin hayvansal atıklarından üretilebilecek biyogaz potansiyeli belirlenip (yaklaşık 15.5 milyon $\mathrm{m}^{3} / \mathrm{y} 1$ ), konum kapasiteleri ve taşıma mesafeleri de göz önünde bulundurularak, 3 farklı biyogaz tesis senaryosu oluşturulmuş, uygun tesis kapasiteleri ile bu tesislerin yatırım maliyetleri hesaplanmıştır. Buna göre, 528 kW kurulu gücü ile Kemah (İliç, Kemah, Refahiye), $1299 \mathrm{~kW}_{\mathrm{e}}$ ile Çayırlı (Otlukbeli, Çayırlı, Tercan) ve $2463 \mathrm{~kW}_{\mathrm{e}}$ ile Erzincan Merkez (Merkez, Üzümlü)'de Biyogaz Enerji Santrallerinin kurulabileceği görülmüştür. Her bir tesis için gerekli olan yatırımın geri ödeme süresi ise yaklaşık 4 yıldır. Bölgede, küçük boyutlarda olmak üzere, önerilen sayıdan daha fazla sayıda biyogaz tesisi kurmak da mümkündür.

Ekonomik açıdan bakıldığında, düşük yatırım maliyetleri, artan verimlilik, sistemin kolay kontrolü ve işletme ve bakımda basitlik ile biyogaz tesislerinin tasarımı Erzincan'da biyogaz üretimini artıracak, böylelikle ulusal şebekeye daha fazla elektrik gücü sağlanabilecektir.

$\mathrm{Bu}$ çalışma, hayvan atıklarının Erzincan' da biyogaz enerjisi ve elektrik enerjisi üretimi için verimli bir şekilde kullanılabilecek ümit vaat eden düşük enerji tüketimine sahip sürdürülebilir enerji kaynağı olduğunu göstermektedir. Biyogaz üretim teknolojisinin enerji üretiminden başka yan ürün olarak organik gübre çıktısı ve çevreye olan olumlu etkileri de Erzincan iline sağlanacak en önemli katkılar arasındadır. Ayrıca, ileride inşa edilebilecek belirli sayıdaki biyogaz tesisine en uygun yerleri tanımlamak için hazırlanabilecek spesifik bölgesel planlama süreçlerine de 1 şık tutacak bir çalışmadır.

\section{Kaynaklar}

Abdeshahian, P., Lim, J. S., Ho, W. S., Hashim, H. and Lee, C. T. (2016). Potential of biogas production from farm nimal waste in Malaysia. Renewable and Sustainable Energy Reviews, 60, 714-723, https://doi.org/10.1016/j.rser.2016.01.117.

Acaroglu, M. and Aydogan, H. (2012). Biofuels energy sources and future of biofuels energy in Turkey. Biomass Bioenergy, 36, 69-76, https://doi.org/10.1016/j.biombioe.2011.10.004.

Achinas S., Achinas V. and Euverink G.J.W. (2017). A Technological Overview of Biogas Production from Biowaste. Engineering, 3(3), 299-307, https://doi.org/10.1016/J.ENG.2017.03.002.

Agayev, E. and Ugurlu, A. (2011). Biogas production from co-digestion of horse manure and waste sewage sludge. Technical Proceedings of the
2011 NSTI Nanotechnology Conference and Expo, NSTI-Nanotech, 3, 657-660.

Akbulut A. and Dikici A. (2004). Elazı̆g ili'nin biyogaz potansiyeli ve maliyet analiz. Doğu Anadolu Bölgesi Araştırmalart Dergisi, 2(2), 36-41.

Akyürek Z. (2019). Energy Recovery From Animal Manure: Biogas Potential of Burdur, Turkey. Eskişehir Technical University Journal of Science and Technology A-Applied Scienceand Engineering, 20(2), 161-170.

Ar F.F. (2018). Ottan Çöpten Enerji. Enerji ve Çevre Dünyası Dergisi, 143, 24-27.

Avcioglu O. and Turker U. (2012). Status and potential of biogas energy from animal wastes in Turkey. Renewable and Sustainable Energy Reviews, 16, 1557-1561, https://doi.org/10.1016/j.rser.2011.11.006.

Berglund, M. and Börjesson P. (2006). Assessment of energy performance in the life-cycle of biogas production. Biomass and Bioenergy, 30, 254266,

https://doi.org/10.1016/j.biombioe.2005.11.011.

BOTAŞ- Boru Hatları İle Petrol Taşıma Anonim Şirketi. (2020, 27 Mayıs). Erişim adresi www.botas.gov.tr/Sayfa/2020-yili-mayis-ayidogal-gaz-toptan-satis-fiyat-tarifesi/494.

Capik, M., Yilmaz, A.O. and Cavusoglu, I. (2012). Present situation and potential role of renewable energy in Turkey. Renewable Energy, 46, 1-13, https://doi.org/10.1016/j.renene.2012.02.031

Cu T.T.T., Nguyen T.X., Triolo J.M., Pedersen L., Le V.D., Le P.D. and Sommer S.G. (2015). Biogas production from Vietnamese animal manure, plant residues and organic waste: influence of biomass composition on methane yield. AsianAustralasian Journal of Animal Sciences, 28(2), 280-289, https://doi.org/10.5713/ajas.14.0312.

Çevik, A. (2016). Çanakkale ilindeki Hayvansal Atıkların Biyogaz Potansiyelinin Değerlendirilmesi. Yüksek Lisans Tezi, Çanakkale Onsekiz Mart Üniversitesi Sosyal Bilimler Enstitüsü, Çanakkale.

Dagnall S., Hill J. and Pegg D. (2000). Resource mapping and analysis of farm livestock manures-assessing the opportunities for biomass-to-energy schemes. Bioresource Technology, 71, 225-234, https://doi.org/10.1016/S0960-8524(99)000760 .

Deloitte: Biyokütlenin altın çağı. (2020, 27 Mayıs). Erişim adresi www2.deloitte.com/content/dam/Deloitte/tr/Doc uments/energy- 
resources/Biyok\%C3\%BCtlenin\%20alt\%C4\%B 1n\%20\%C3\%A7a\%C4\%9F\%C4\%B1Sonnn.pdf

Demirbaş, A. (2011). Competitive liquid biofuels from biomass. Applied Energy, 88(1), 17-28, https://doi.org/10.1016/j.apenergy.2010.07.016.

EA-Enerji Atlası. (2020, 27 Mayıs). Erişim adresi https://www.enerjiatlasi.com/biyogaz/.

Ekpeni, L.E.N., Benyounis, K.Y., Ekpeni, F. N., Stokes, J. and Olabi, A. G. (2014). Energy diversity through renewable energy source (RES) - A case study of biomass. Energy Procedia, 61, 1740 1747.

EPDK- Enerji Piyasası Düzenleme Kurumu. (2020, 27 Mayıs). Erişim adresi www.epdk.gov.tr/Detay/DownloadDocument?id $=\mathrm{Hqo87qC} 1 \mathrm{k} 6 \mathrm{Q}$.

Ersoy E. and Ugurlu A. (2020). The potential of Turkey's province-based livestock sector to mitigate GHG emissions through biogas production. Journal of Environmental Management, 255, 109858, https://doi.org/10.1016/j.jenvman.2019.109858.

Eryilmaz T., Yesilyurt M.K., Gokdogan O. and Yumak B. (2015). Determination of biogas potential from animal waste in Turkey: A case study for Yozgat province. European Journal of Science and Technology, 2(4), 106-111.

Gebrezgabher S.A., Meuwissen M.P.M., Prins.B.A.M. and Lansink A.G.J.M.O. (2010). Economic analysis of an aerobic digestion - a case of green power biogas plant in The Netherlands. NJAS Wageningen Journal of Life Sciences, 57, 109115.

Gürdil G.A.K., Baz Y.Ö., Demirel Ç. and Demirel B. (2015). Yakıt peleti ve briketi için güncellenmiş avrupa birliği standartları ve ilgili parametreler. Uludă̆ Üniversitesi Ziraat Fakültesi Dergisi, 29(2), 147-156.

Hol-Nielsen J.B., Al-Seadi T. and Oleskowicz P. (2009). The future of anaerobic digestion and biogas utilization. Bioresource Technology, 100, 54785484, https://doi.org/10.1016/j.apenergy.2013.07.005.

Höhn, J., Lehtonen, E., Rasi, S. and Rintala, J. (2014). A geographical information system (GIS) based methodology for determination of potential biomasses and sites for biogas plants in southern Finland. Applied Energy, 113, 1-10.

Ilgar R. (2016). A study for determination of biogas potential in Çanakkale, Assets by Animals. Eastern Geographical Review, 35, 89-106.
Kaya, D. ve Öztürk, H. H. (2012). Biyogaz Teknolojisi Üretim - Kullanım - Projeleme. İstanbul: Umuttepe yayınları.

Kilickaplan, A., Bogdanov, D., Peker, B., Caldera, U. and Aghahosseini, A. (2017). An energy transition pathway for Turkey to achieve $100 \%$ renewable energy powered electricity, desalination and non-energetic industrial gas demand sectors by 2050. Solar Energy, 158, 218-235, https://doi.org/10.1016/j.solener.2017.09.030.

Kurnuç Seyhan A. ve Badem A. (2018). Erzincan ilindeki hayvansal atıların biyogaz potansiyelinin araştırılması. Akademik Platform Mühendislik ve Fen Bilimleri Dergisi, 6(1), 2535 .

Lonnqvist T., Sanches-Pereira A. and Sandberg T. (2015). Biogas potential for sustainable transport e a Swedish regional case. Journal of Cleaner Production, 108, 1105-1114, https//doi.org/10.1016/j.jclepro.2015.07.036.

Moreda L. (2016). The potential of biogas production in Uruguay. Renewable and Sustainable Energy Reviews, 54, 1580-1591, https://doi.org/10.1016/j.rser.2015.10.099.

Nacar Koçer N. ve Kurt G. (2013). Malatya'da hayvancılık potansiyeli ve biyogaz üretimi. Sakarya Üniversitesi Fen Bilimleri Enstitüsü Dergisi, 17(1), 1-8.

Özer B. (2017). Biogas energy opportunity of Ardahan city of Turkey. Energy, 139, 1144-1152, https://doi.org/10.1016/j.energy.2017.07.052.

Öztürk, H. (2012). Enerji Bitkileri ve Biyoyakıt Üretimi. İstanbul: Hasad Yayınc1lık.

Öztürk, M. (2017). Hayvan Gübresinden Biyogaz Üretimi. Ankara: T.C. Çevre ve Şehircilik Bakanlığı.

Palm R. (2010). The economic potential for production of upgraded biogas used as vehicle fuel in Sweden. Technical report no FRT 2010:03, Chalmers University of Technology, Göteborg, Sweden. Erişim adresi http://publications.lib.chalmers.se/records/fullte $\mathrm{xt} / 126342 . p d f$

REN21 (2019). Renewable Energy Policy Network for the 21st Century, Global Status Report, Paris. Erişim adresi https://www.ren21.net/reports/global-statusreport/

Rios M. and Kaltschmitt M. (2016). Electricity generation potential from biogas produced from organic waste in Mexico. Renewable and 
Sustainable Energy Reviews, 54, 384-395, https://doi.org/10.1016/j.rser.2015.10.033.

Scarlat, N., Fahl, F., Dallemand, J. F., Monforti, F. and Motola, V. (2018). A spatial analysis of biogas potential from manure in Europe. Renewable and Sustainable Energy Reviews, 94, 915-930, https://doi.org/10.1016/j.rser.2018.06.035.

SELEDA-Seleda Gübre. (2020, 27 Mayıs). Erişim adresi www.seleda.com.tr.

TCMB-Türkiye Cumhuriyeti Merkez Bankası. (2020, 27 Mayıs). Erişim adresi www.tcmb.gov.tr/kurlar/kurlar_tr.html.

Tolay, M., Yamankaradeniz, H., Yardımcı, S. and Reiter, R. (2008). Hayvansal atıklardan biyogaz üretimi. 2008 VII. Ulusal Temiz Enerji Seтроzуити (UTES) (ss.259-264). İstanbul.

Tufaner F., Avşar Y., Dere T. ve Gönüllü T. (2013). Türkiye'de biyogaz tesisi projelerinde başarı ve başarısızlık nedenlerinin analizi ve merkezi biyogaz tesislerinin önemi. 2013 I. Ulusal Kompost ve Biyogaz Çalıştayı. Antalya.

TUİK-Türkiye İstatistik Kurumu hayvan istatistikleri. (2020, 27 Mayıs). Erişim adresi https://biruni.tuik.gov.tr/medas/?kn\%C2\%BC10 1\&locale\%C2\%BCtr.
Türker M. (2008). Anaerobik Biyoteknoloji ve Biyoenerji Üretimi.İzmir: Çevkor Vakfı Yayınları.

Uddin W., Khan B., Shaukat N., Majid M., Mehmood A., Ali S.M., Younas U., Anwar M., Mujtaba G. and Almeshal A.M. (2016). Biogas potential for electric power generation in Pakistan: A survey. Renewable and Sustainable Energy Reviews, 54, 25-33, https://doi.org/10.1016/j.rser.2015.09.083.

Yağlı H. ve Koç Y. (2019). Hayvan gübresinden biyogaz üretim potansiyelinin belirlenmesi: Adana ili örnek hesaplama. Çukurova Üniversitesi Mühendislik Mimarlık Fakültesi Dergisi, 34(3), 35-48.

YEGM-Yenilenebilir Enerji Genel Müdürlüğü. (2020, 27 Mayıs). Erişim adresi http://www.yegm.gov.tr/yenilenebilir/biyogaz.a spx.

Yürük F. ve Erdoğmuş P. (2015). Düzce ilinin hayvansal atıklardan üretilebilecek biyogaz potansiyeli ve K-Means kümeleme ile optimum tesis konumunun belirlenmesi. Ileri Teknoloji Bilimleri Dergisi, 4(1), 47-56. 